\title{
Sources of health information used by Qatari adolescents
}

Klaus Schoenbach ${ }^{1}$

${ }^{1}$ Northwestern University, Doha, Qatar. (Correspondence to: klaus.schoenbach@northwestern.edu).

\begin{abstract}
Background: In Qatar, health media campaigns and applications (apps) have not been particularly successful among adolescents. Arab culture suggests personal communication as a promising alternative.
\end{abstract}

Aims: This study aimed to assess the importance of personal communication for health information among Qatari adolescents compared with other sources.

Methods: A secondary analysis of a representative sample of 1117 Qatari adolescents was done in 2017 of their sources of health information. Data were analysed according to age group and sex.

Results: Personal communication was the most important source of health information (particularly parents and friends), together with a few selected Internet platforms for both sexes and age groups. Significantly more females used parents and Instagram as a source of health information than males $(P \leq 0.01)$. Males used traditional media channels, online forums and Facebook significantly more often than females (all $P<0.001$ ). Siblings, doctors/nurses, Twitter and Wikipedia were significantly more important for older adolescents $(P<0.05)$. Younger respondents relied on YouTube and health classes significantly more than older adolescents $(P<0.05)$.

Conclusions: Providers of health information for adolescents should take advantage of personal communication and pay attention to which Internet channels are used. Parents and friends are particularly important sources of health information.

Keywords: adolescents, health, health information, media of communication, Qatar

Citation: Schoenbach K. Sources of health information used by Qatari adolescents. East Mediterr Health J. 2020;26(8):971-975. https://doi.org/10.26719/ emhj.19.063

Received: 17/10/18; accepted: 30/04/19

Copyright (C) World Health Organization (WHO) 2020. Open Access. Some rights reserved. This work is available under the CC BY-NC-SA 3.0 IGO license (https://creativecommons.org/licenses/by-nc-sa/3.o/igo).

\section{Introduction}

Qatar is a country with health problems among its adolescents $(1-3)$. The authorities have tried to convince them to become more health-conscious through campaigns and an online application (app) $(3,4)$. So far, not a single recent campaign has reached most Qatari adolescents (3) and the app has only been "ever downloaded or used" by $5 \%$ of Qatari adolescents (3).

Scattered evidence about alternative sources of health information has already hinted at family and friends as the most used channels in Qatar, followed by the Internet $(5,6)$. In the Gulf region, personal communication appears important as well (7-9), as also in South America $(10,11)$ and Europe, North America, Australia and New Zealand (12), above all among adolescents (4,13-22). Arab culture should even strengthen the role of personal communication since it is more relationship-based (23) where personal connections play an important role (24) and social behaviour tends be more 'other-directed,' i.e., more determined by one's family, elders and peers (25).

In particular, adolescents' friends should be a promising personal source for health information. Research has found that adolescents from 12 years upwards become increasingly less dependent on their parents (26). Instead, they are receptive to approval or disapproval from peers outside the family; this seems even more the case among females (27). Thus, personal sources seem to be particularly promising for reaching young people with health information, specifically in Arab cultures. Among these sources, the importance of adolescents' friends has been emphasized (26).

The objectives of this study were to examine how popular personal contacts are for general health information among Qatari teenagers, specifically the role of friends, when compared to other sources of information. Research on sex and peer orientation (27) suggests two hypotheses: H1) female adolescents consult their friends more often than males for health information; and $\mathrm{H} 2$ ) the older adolescents are, the more often they consult their friends for health information (26).

\section{Methods}

This study is a secondary analysis of a large representative survey of Qatari adolescents aged 13-20 years in order to gauge their health information behaviour (3). Informed consent was obtained beforehand from both the adolescents and their parents. The survey was commissioned by Northwestern University in Qatar, administered by the Social and Economic Survey Research Institute, Qatar University, and conducted in Arabic on laptop 
computers at schools, from 22 April to 17 May 2017. In total, 1117 Qatari nationals participated (response rate: 72\%).

The sources for health information that Qatar's adolescents turn to was addressed by the question: "People get information about health from many different sources. For each of the following sources please indicate whether you have used them at all to get information about health topics." Possible answers were "yes", "no", "refused" and "not applicable" (3). The 23 sources presented to respondents were compiled into the following categories:

- Personal sources: guardians (parents in most cases), siblings, friends, doctors/nurses;

- Websites: YouTube, Wikipedia, SahtakAwalan (Qatari health website), a medical website, online forums about health information, newspaper articles (online version), magazine articles (online version);

- Social media: Facebook, Snapchat, Twitter, Instagram;

- Traditional media: television (TV) news, TV shows (talk shows, reality shows, medical or other dramas), newspaper articles (print version), magazine articles (print version), radio, books;

- Other: leaflets/pamphlets (from a hospital, clinic or medical practice), health classes in school.

To test $\mathrm{H} 1$ and $\mathrm{H} 2$, the responses of females and males, and younger and older adolescents were compared. In the survey, sex was addressed by the question "What is your gender?" with responses "I am a female" and "I am a male" (50\% of the respondents each). The age of the respondents was gauged by "What is your age in years?" (3). The median age divided the respondents into a younger cohort (13-15 years, $45 \%$ of the respondents) and an older cohort (16-20 years, 55\%).

The chi-square or Fisher exact test (one-sided) was used to assess the statistical significance of differences between these groups. A $P$-value $\leq 0.05$ was considered statistically significant.

\section{Results}

For more than three quarters of all respondents and for their four subgroups separately, personal sources were the most popular source for health information, in this order: parents, friends, siblings and doctors/nurses. One website (YouTube) and two social-media platforms (Instagram and Snapchat) were equally important. Fewer Qatari adolescents mentioned other social-media platforms and websites, or more traditional sources such as medical leaflets/pamphlets, TV, books and health classes. Radio, printed newspapers and magazines were consulted by about $30 \%$ of respondents (Table 1 ).

$\mathrm{H} 1$ (females consult friends more often than males) was not confirmed. On the contrary, parents were a more usual source of health information for females than for males $(P<0.001)$, and also Instagram $(P=0.01)$. Males, in contrast, used traditional media channels (TV news, print media and radio) significantly more often than females, as well as online forums, Facebook and heath classes (all $P<0.05)$.

$\mathrm{H} 2$ (the older adolescent are, the more friendsoriented they become) was also not confirmed. Siblings ( $P$ $<0.001)$ and doctors/nurses $(P=0.04)$ were significantly more important for older adolescents, as were Twitter $(P$ $=0.02)$ and Wikipedia $(P=0.05)$. Younger respondents relied on YouTube $(P=0.05)$ and health classes $(P=0.03)$ significantly more than older adolescents.

\section{Discussion}

This analysis supports the assumption that personal sources of health information are the most important among Qatari adolescents. In Qatar, only two social-media platforms (Instagram and Snapchat) and one website (YouTube) were close in usage to personal sources. This result was valid equally for females and males, and younger and older adolescents.

Among the personal sources, and as predicted by previous research (26), friends are extremely important, surpassed only slightly by parents. Females and males, and younger and older adolescents rely equally on their friends as sources of health information. Therefore, assumptions that females and older adolescents should be more friends-oriented $\left(\mathrm{H} 1\right.$ and $\left.\mathrm{H}_{2}\right)$ are not supported. Instead, females depend slightly more than males on their parents for health information in general, which would contradict previous evidence (27). In contrast to the concept of moral development (26), the dominant role of the family in Qatari culture, especially that of parents, would appear to prevail even among females and older adolescents.

As a promising conclusion, health campaigns for adolescents in Arab countries should take advantage of personal communication with parents and friends to disseminate health information, supported by careful use of specific Internet platforms.

\section{Limitations}

Friends as sources of health information might possibly be more popular than measured in this secondary analysis because they could also be the unmentioned sources of health information on social media. Also, since this study is about health information in general, it could well be that adolescents use personal sources even more extensively the more serious the health issues are (9).

\section{Funding: None.}

Competing interests: None declared. 


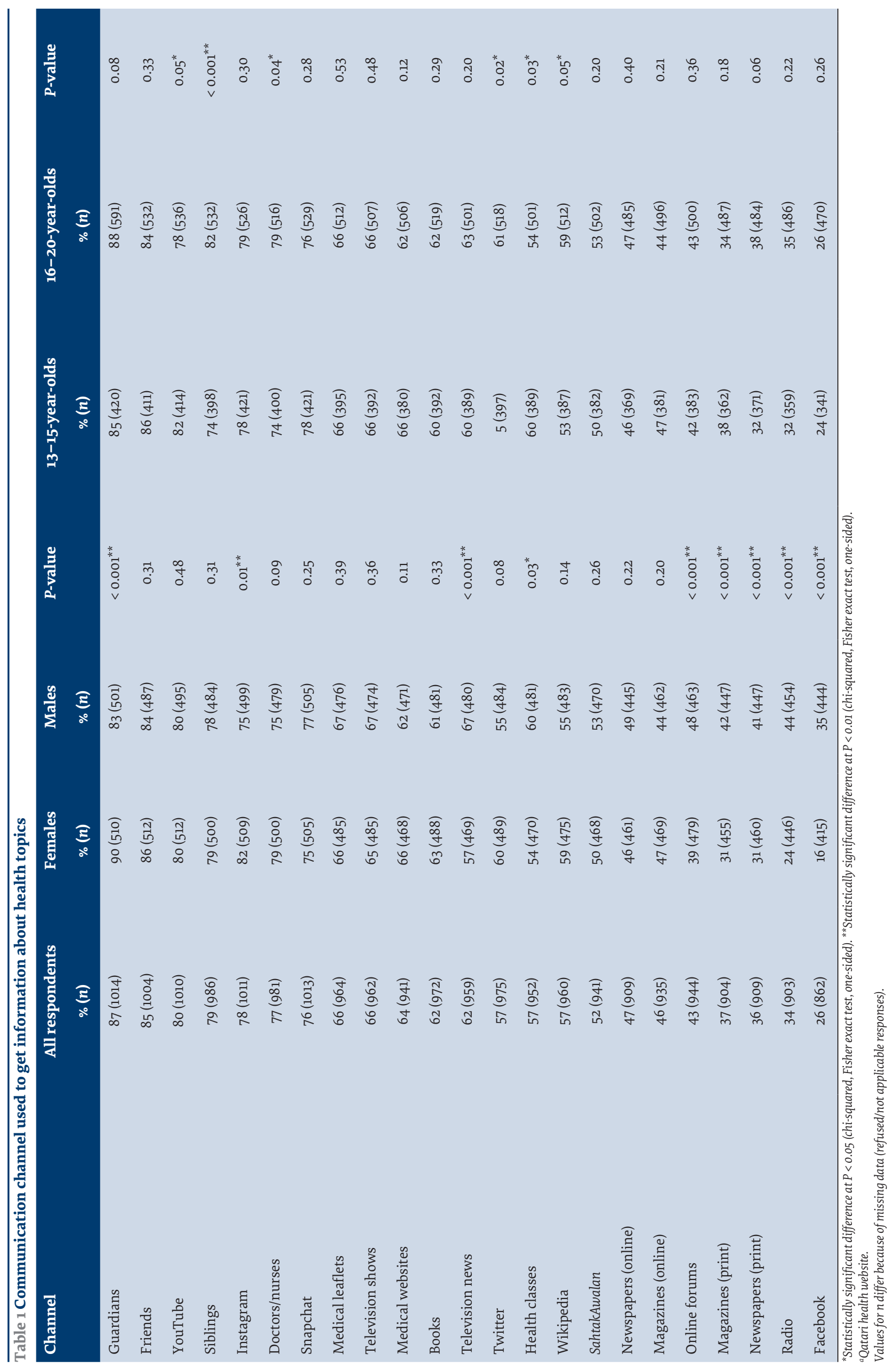




\section{Sources d'information sanitaire utilisées par les adolescents qatariens}

\section{Résumé}

Contexte : Au Qatar, les campagnes médiatiques et les applications dans le domaine de la santé n'ont pas eu beaucoup de succès auprès des adolescents. Dans la culture arabe, la communication personnelle semble être une alternative prometteuse.

Objectifs: La présente étude visait à évaluer l'importance de la communication personnelle pour la diffusion d'informations sanitaires auprès des adolescents qatariens, en comparaison avec d'autres sources.

Méthodes: Une analyse secondaire des sources d'information sanitaire a été réalisée dans un échantillon représentatif de 1117 adolescents qatariens en 2017. Les données ont été analysées en fonction du groupe d'âge et du sexe.

Résultats : La communication personnelle était la principale source d'information sanitaire (notamment avec les parents et les amis), ainsi qu'un nombre limité de plateformes Internet pour chaque sexe et groupe d'âge. Les filles étaient nettement plus nombreuses que les garçons à recueillir des informations sanitaires auprès de leurs parents et sur Instagram $(p \leq 0,01)$. Les garçons utilisaient les médias traditionnels, les forums en ligne et Facebook beaucoup plus fréquemment que les filles (en tout, $p<0,001$ ). Les frères et sœurs, les médecins et le personnel infirmier, ainsi que Twitter et Wikipédia, constituaient des sources significativement plus importantes pour les adolescents plus âgés $(p<0,05)$. Les répondants plus jeunes s'appuyaient sur YouTube et les cours de santé de manière significativement plus importante que les adolescents plus âgés $(p<0,05)$.

Conclusions: Les fournisseurs d'informations sanitaires destinées aux adolescents devraient tirer profit de la communication personnelle et faire attention aux canaux Internet qui sont utilisés. Les parents et les amis sont des sources particulièrement importantes d'informations sanitaires.

$$
\text { كلاوس شونبادر المعلومات الصحية التي يستخدمها المر اهقون القطريون }
$$

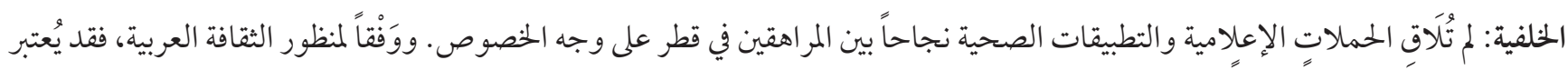
التو اصل الشخَصِي بديلاً واعداً.

الأهداف: هدفت هذه الدراسة إلى تقييم أهمية التو اصل الشخصي كمصدر لحصول المر اهقين القطريين على معلومات صحية مقارنةً بمصادر أخرى.

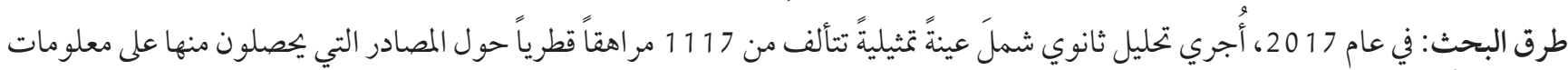

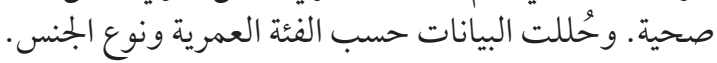

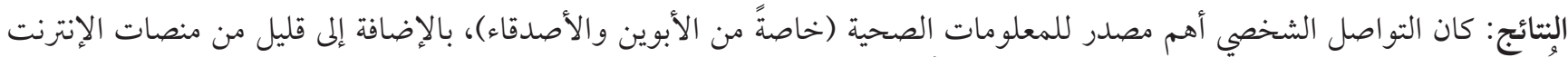

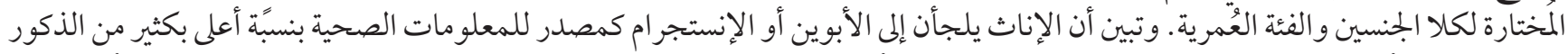

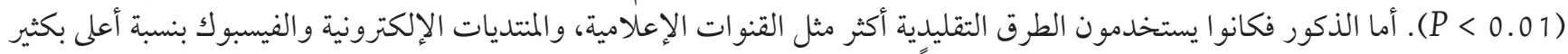

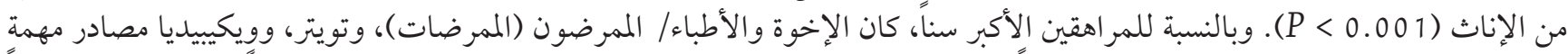

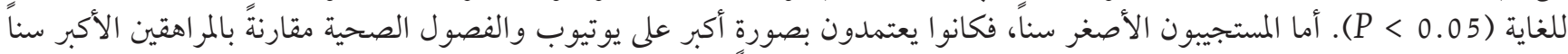

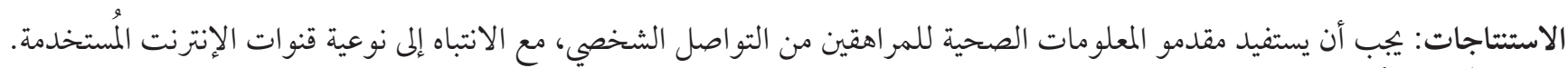

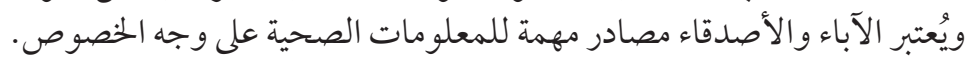

\section{References}

1. Abdel-Khalek, AM. The relationships between subjective well-being, health, and religiosity among young adults from Qatar. Ment Health, Relig Cult. 2013;16:306-18. https://doi.org/10.1080/13674676.2012.660624

2. Ng M, Fleming T, Robinson M, Thomson B, Graetz N, Margono C, et al. Global, regional, and national prevalence of overweight and obesity in children and adults during 1980-2013: A systematic analysis for the Global Burden of Disease Study 2013. Lancet. 2014;384(9945):766-81. https://doi.org/10.1016/S0140-6736(14)60460-8

3. Schoenbach K, Wartella E, Saeed M, Khaled SM. Health information and monitoring among Qatari adolescents, 2017. Doha, Qatar: Northwestern University in Qatar; 2017 (https://www.qatar.northwestern.edu/docs/publications/research/2017-health-ren port.pdf, accessed 3 September 2019). 
4. Colineau N, Paris C. Talking about your health to strangers: understanding the use of online social networks by patients. New Rev Hypermedia Multimed. 2010;16(1-2):141-60. https://doi.org/10.1080/13614568.2010.496131

5. Choudhury SM, Arora T, Alebbi S, Ahmed L, Aden A, Omar O, et al. How do Qataris source health information? PLoS One. 2016;11(11):e0166250. https://doi.org/10.1371/journal.pone.0166250

6. Media use in the Middle East, 2017. Doha, Qatar: Northwestern University in Qatar; 2017.

7. Al Ghamdi KM, Almohedib AM. Internet use by dermatology outpatients to search for health information. Int J Dermatol. 2011;50(3):292-9. https://doi.org/10.1111/j.1365-4632.2010.04705.x

8. Al Ghareeb AA. The role of health information resources in forming the health awareness of Saudi women: applied study in Riyadh. J Soc Sci. 2009;37(2).

9. Arnott Smith A, Keselman A. Meeting health information needs outside of healthcare: opportunities and challenges. Amsterdam: Elsevier; 2015.

10. Airhihenbuwa CO. Health and culture: Beyond the Western paradigm. Thousand Oaks, CA: Sage; 1995.

11. Elder JP, Ayala GX, Para-Medina D, Talavera DA. Health communication in the Latino community: Issues and approaches. Annu Rev Public Health. 2009;30:227-51. https://doi.org/10.1146/annurev.publhealth.031308.100300

12. Rossmann C, Lampert C, Stehr P, Grimm M. Nutzung und Verbreitung von Gesundheitsinformationen: Ein Literaturueberblick $\mathrm{zu}$ theoretischen Ansaetzen und empirischen Befunden [Use and distribution of health information: a literature review of theoretical approaches and empirical evidence]. Guetersloh, Germany: Bertelsmann Stiftung; 2018.

13. Lariscy RW, Reber BH, Paek H. Examination of media channels and types as health information sources for adolescents: comparisons for black/white, male/female, urban/rural. Journal of Broadcasting \& Electronic Media. 2010;54(1):102-10. https://doi. org/10.1080/08838150903550444

14. Zhao S. Parental education and children's online health information seeking: beyond the digital divide debate. Soc Sci Med. 2009;69(10):1501-5. https://doi.org/10.1016/j.socscimed.2009.08.039

15. Center on Media and Human Development. Teens, health, and technology: a national survey. Evanston (IL): Northwestern University, School of Communication; 2015.

16. Diiorio C, Pluhar E, Belcher L. Parent-child communication about sexuality: a review of the literature from 1980-2002. J HIV/ AIDS Prev Educ Adolesc Child. 2003;5(3-4):7-32. https://doi.org/10.1300/J129v05no3_02

17. Ennett ST, Bauman KE, Foshee VA, Pemberton M, Hicks KA. Parent-child communication about adolescent tobacco and alcohol use: what do parents say and does it affect youth behavior? J Marriage Fam. 2001;62(1):48-62. https://doi.org/10.1111/j.17413737.2001.00048.x

18. Gowen LK. Online mental health information seeking in young adults with mental health challenges. J Technol Hum Serv. 2013;31(2): 97-111. https://doi.org/10.1080/15228835.2013.765533

19. Harakeh Z, van Nijnatten CHCJ. Young people smokers' reactions on peer influence not to smoke. Subst Use Misuse. 2016;51(13):1693-700. https://doi.org/10.1080/10826084.2016.1191517

20. Harvey KJ, Brown B, Crawford P, Macfarlane A, McPherson A. 'Am I normal?' Teenagers, sexual health and the internet. Soc Sci Med. 2007;65:771-81. https://doi.org/10.1016/j.socscimed.2007.04.005(4)

21. Hu Y, Sundar SS. Effects of online health sources on credibility and behavioral intentions. Commun Res. 2009;37(1):105-32. https://doi.org/10.1177/0093650209351512

22. Hutchinson MK, Jemmott III JB, Jemmott LS, Braverman P, Fong JT. The role of mother-daughter sexual risk communication in reducing sexual risk behaviors among urban adolescent females: a prospective study J Adolesc Health. 2003;33(2): 98-107. https://doi.org/10.1016/S1054-139X(03)00183-6

23. Hooker JN. Cultural differences in business communication. In: Paulston CB, Kiesling SF, Rangel ES, editors. Handbook of intercultural discourse and communication. Maladen (MA): Wiley-Blackwell; 2012:389-407.

24. Hofstede G. Culture's consequences: international differences in work-related values, 2nd edition. Beverly Hills (CA): Sage; 1984.

25. Riesman D, Glazer N, Denney R. The lonely crowd: a study of the changing American character. New Haven (CT): Yale University Press; 1950.

26. Kohlberg L. Stage and sequence: the cognitive-developmental approach to socialization. In: Goslin DS, editor. Handbook of socialization theory and research. Chicago (IL): Rand McNally; 1969:347-480.

27. Rose AJ, Rudolph KD. A review of sex differences in peer relationship processes: Potential trade-offs for the emotional and behavioral development of girls and boys. Psychol Bull. 2006;132(1):98-131. https://doi.org/10.1037/0033-2909.132.1.98 